\title{
10. Public-private partnerships in education assessed through the lens of human rights
}

\section{Mireille de Koning}

\section{INTRODUCTION}

The theoretical debate on the potential benefits and disadvantages of public-private partnerships (PPPs) in education is an ongoing one. Yet there is little analysis of the effects of a diverse range of PPPs on communities and education practices, including how providers in partnerships interact with the state and affect the overall system, positively or negatively (Robertson et al., 2012; Languille, 2017). Many governments, particularly in the global South, that have implemented some type of PPP in education have yet to develop and implement adequate regulatory frameworks to ensure accountability within partnership arrangements. While increasingly promoted and supported as an innovative and costeffective policy approach to deliver education, PPPs also give rise to several concerns related to equity and accountability. 'Partnerships' may fall outside legal and regulatory mechanisms (Draxler, 2008). Access to information (Minow, 2003) and agreements may be developed in parallel to, rather than in alignment with, existing state education sector plans and contribute little to building state capacity. Rather than expanding social services, they may create and entrench inequalities in educational access and quality. These concerns are particularly pertinent in contexts faced with disrupted provision, low public spending and inadequate regulatory and monitoring capacities in education.

This chapter discusses concerted efforts undertaken by a growing body of national and international civil society organizations from 
the education and human rights fields to bring a human rights perspective to the discourse around the implications of the increased involvement of private actors in education. This work, involving research and advocacy in several countries and spanning approximately four years, has resulted in a developing interpretation of the application of the human rights framework to the role of private actors and public-private partnership arrangements in education, including a series of statements from UN bodies based on empirical country cases. Research on the direct outcomes and broader impact of PPPs is growing. In parallel, the Open Society Foundations Education Support Program has convened a range of education stakeholders in different fora to critically reflect on various PPP models. These stakeholders have examined contexts in which partnerships have been implemented, focusing on policy options, and issues of accountability and state capacity in fragile contexts. Combined, these legal developments and broad stakeholder engagements have fed into an ongoing process aiming to develop a set of human rights Guiding Principles on how states should address private education provision.

These convenings and the process for the development of the guiding principles have given rise to specific areas of debate, including under what (legal) conditions, if any, governments can fund private schooling compatible with their human rights obligations. Stakeholder critics are, naturally, not uniform in their positions. Some take the stance that private education should be severely controlled and that any framework that does not fully preclude models of private provision that depends on public funding directly or indirectly should be prohibited. Others, reflected in the work described here, take a pragmatic view, pushing for application of existing legal frameworks and focusing on human rights principles to address the role and limitations of PPPs in education.

This chapter reports on these convenings and highlights several issues and areas of debate or consensus emerging from them. In turn, the development of norms in relation to PPPs in education is discussed. Finally, the chapter will conclude that the ongoing development of a normative framework is built on a process of informed and critical reflection by different stakeholders attempting to navigate and find a way forward in a contentious debate on the role of private actors in education. 


\section{CONTESTED POLICY APPROACH AND AMBIGUOUS MEANING}

Public-Private Partnerships (PPPs) are a relatively new and highly contested phenomenon in the global education space, both as a policy idea and subject of specific interventions on the ground. Despite a dearth of analysis on the effects of PPPs in education, the contracting of the private sector by states under different arrangements, including private operation of public schools, subsidized (for-profit) private education delivery and voucher schemes have since the late 1990s been promoted as innovative, effective and flexible policy approaches to expand education and to address a range of challenges related to access and quality, particularly in low- and middle-income countries in Africa, Asia and Latin America. In the context of the Sustainable Development Goals, partnership arrangements are expected to play an important role in implementing strategies for realizing the goals and targets under the Sustainable Development Goal for education, SDG4, with SDG 17 promoting the use of partnerships between governments, the private sector and civil society to address inequalities in the provision of and access to public services.

At the same time, PPPs have given rise to concerns and challenges related to equity, accountability, social cohesion and effectiveness. Emerging research on diverse PPPs interventions in different contexts both in high- and low-income countries including Chile, Colombia, India, Pakistan, Sweden, Uganda, the UK and the US, ${ }^{1}$ has found evidence that these have created or reinforced existing segregation within systems, depressed teachers' pay, and have accelerated processes of education privatization, among other implications.

Part of the controversy around PPPs can be attributed to their disputed meaning. PPP is a vague and ambiguous term open to varied interpretation by different actors and used to denote a

1 Most of the research on the effects of PPPs has been undertaken in Latin America (Chile), Europe (UK) and the US, with fewer studies in Africa (e.g., Uganda, Ghana) and Asia (e.g., Pakistan). For recent reviews of education PPPs in different contexts globally, see: Robertson Aslam, Rawal, and Saeed (2017) and Languille (2017). 
multiplicity of PPP mechanisms with different rationales, motivations and expectations (Robertson et al., 2012; Languille, 2017). This is further complicated by the fact that the implementation and impacts of PPPs are highly context-specific (Verger and Moschetti, 2017) and dependent on the different actors (public and private) involved and the (power) relationship between them, as well as the "nature and history of both the public and private sectors in particular regions, and countries" (Gideon and Unterhalter, 2017). In education, PPPs generally relate to arrangements that involve public funding for services directly provided or managed by private actors, conversely framed as formal contracts between governments and private-sector providers for specific services (Patrinos, Barrera Osorio, and Guaqueta, 2009) or more broadly, as joint initiatives focused on shared objectives in delivering a social service. The common feature of most PPPs is the new or additional roles ascribed to private actors (Robertson et al., 2012), usually taking on operational responsibilities previously exercised by the state, and a shift of the state's role, away from direct service provision and more focused on the funding, supervision and regulation of systems.

There thus exists a fundamental tension between public (state) accountability and commercial motivation in most PPP arrangements. In an article on the political and social implications of partnering with the private sector, Verger and Moschetti (2017) observe that many proposed PPP interventions "do not differ significantly from privatization and marketization policies and, in fact, share the most important assumptions about the benefits of private provision and market competition" (Verger and Moschetti, 2017: 250). School choice, diversification and competition are core dimensions promoted by PPP advocates for the implementation of charter schools and voucher programmes to expand education in developing countries and poor communities. In her review of PPPs in the education and health sectors in developing countries, Languille (2017), however, finds that these principles, in particular cost-efficiency in social service delivery targeting poor communities, is rarely realized in practice. Further she argues that there is almost no empirical application of a social justice frame to an analysis of PPPs in social services. 


\section{PUBLIC-PRIVATE PARTNERSHIPS IN CONFLICT-AFFECTED AND FRAGILE CONTEXTS}

In June 2016, the Open Society Foundations Education Support Program (OSF-ESP) and the Inter-Agency Network for Education in Emergencies (INEE) jointly convened a range of actors ${ }^{2}$ in a two-day roundtable in New York for an open and critical exploration of the potential and challenges of, and key considerations in relation to, public-private partnerships in crisis-affected and fragile contexts. Participants included stakeholders from and experts on countries and contexts such as Haiti, New Orleans, Liberia and Pakistan. The impetus for this convening was the announced launch of a pilot multi-operator public-private partnership scheme in pre-primary and primary education by the government of Liberia at the beginning of 2016, in which it would outsource the management of 93 government schools to eight private organizations, including companies and charities. This decision, in particular the possibility that the pilot could develop into a full-scale charter school system, prompted criticism and concern from a variety of stakeholders. Critics included civil society organizations, teachers' organizations and the then UN Special Rapporteur on the Right to Education, Kishore Singh, and generated significant international media coverage ${ }^{3}$ and scrutiny. The project was deemed especially contentious as it originally involved only one partner, the commercial for-profit chain of low-fee private schools, Bridge International Academies, whose activities in Kenya and Uganda have been much criticized and debated. ${ }^{4}$

The move re-ignited discussions on PPPs in education, drawing attention to a pattern of increased involvement of and various

2 Participants included approximately 50 representatives of civil society organizations, academics and researchers, bi-lateral donors and foundations, private providers, ministries of education, teachers' organizations and international organizations. 14 June).

See: Mungai (2016), Al Jazeera. The Stream (2016); and Rosenberg (2016,

4 See the dedicated webpage on the Global Initiative for Social and Economic Rights website that compiles information on the operations of Bridge International Academies in different countries: http:/globalinitiative-escr.org/ advocacy/privatization-in-education-research-initiative/commercial-schools-and-theright-to-education/. 
partnership arrangements with private actors in crisis and post-crisis contexts, including Haiti, New Orleans in the United States, Pakistan and Liberia. Other factors that made the discussion timely and relevant included a rise in international aid to states facing increasingly protracted crises, ${ }^{5}$ an increase in the number of states considering PPPs involving contracting-out schemes within their education systems to address resource and capacity gaps (Rose and Greeley, 2016), and a growing interest in innovative financing methods to increase available funds for education in emergencies involving private actors). The Inter-Agency Network for Education in Emergencies (INEE) and OSF considered the convening an "opportune moment to give broad consideration to the potential role of public private partnerships as a viable policy option for systemic development while reviewing the principles States should follow in developing a PPP to ensure that they meet their international commitments and human rights obligations in doing so" (OSF and INEE, 2016). The roundtable was framed as an occasion to develop an understanding of the current discourse and to identify key considerations in relation to PPPs in contexts where states are faced with severe capacity constraints and systemic challenges in education. Specifically, the convening sought to explore a range of approaches and models of public funding of private schools (in the form of vouchers or charter schools), share lessons from contexts where PPPs have been implemented in education and identify points of agreement on basic principles to follow in the development of PPPs that promote transparency, accountability and equity in education systems.

Some of the key interrelated issues and points of agreement that have come out of this dialogue allow for the consideration of the principles under which states might develop or limit PPPs in education in keeping with their human rights obligations. ${ }^{6}$ The issues and points of agreement discussed were:

\footnotetext{
5 For example, the proposed establishment of an Education Crisis Platform that developed out of the 2015 Oslo Summit on Education for Development that proposes, among other aims, to mobilize and disburse additional and predictable resources for education in fragile and crisis-affected countries and communities. The Global Partnership for Education has also become a significant financer of countries categorized as fragile or conflict-affected.

6 An elaboration of these key considerations and a summary of the discussion can be found in the report of the roundtable, "Exploring Public Private Partnerships
} 
Transparency and stakeholder participation. The design and implementation of an education PPP is a high-stakes process. Interventions affect school communities and through them have wider societal implications, particularly in the case of wide-scale implementation (in countries for example like Chile or Haiti). Nonetheless, many PPPs are found to be developed and agreed without public consultation and a careful assessment before implementation of their potential impact on equity and contribution to the right to education. Teachers' organizations, in particular, are often found to be absent from discussions on PPPs in education (Draxler, 2012). Partnership arrangements must be developed through democratic debate and transparency.

The issue of transparency and stakeholder participation closely relates to risk assessments, by which states are expected to conduct an assessment for any decisions to increase private sector involvement in the education sector. Such assessments should be holistic, taking into account effects and implications related to equity, access to education, and educational outcomes. More often than not considerations of PPP frameworks often do not take into account potential human rights risks such as discrimination or exclusion based on ability. In Uganda just to give one example, several PPP schools were found not to have appropriate facilities and support structures for children with disabilities (ISER, 2016). Similarly, the New Orleans school reforms following Hurricane Katrina that turned over the majority of the city's schools to charter management organizations was found to increase stratification and segregation resulting from 'cream skimming' and selection practices by schools and "encouraged exclusion of struggling students from schools altogether" (Adamson and Darling-Hammond, 2016: 158).

Risk assessments are particularly important for examining the consequences of a partnership ending at the responsibility of the private partner (through abandonment, insolvency, or failure to meet contractual responsibilities) leaving the state responsible for damage control and needed additional resources. An example here, albeit from a country not faced with a disruptive crisis, is the development of publicly-funded private schools - so-called "free

in Crisis-affected \& Fragile States: Roundtable Report.” Retrieved 6 February 2018 from http://s3.amazonaws.com/inee-assets/page-images/OSF-INEE_PPP-round table_framing-paper_Novelli_crisis-contexts.pdf. 
schools" - in Sweden where a series of education reforms in the early 1990s included the decentralization of responsibility for education to local municipalities and the introduction of school choice for students and parents (OECD, 2015). By 2013 nearly 800 free schools competing with public schools for government funds, many of them operated by for-profit companies, had been set up across the country; 2013 was also the year in which one of the companies operating free schools declared bankruptcy, selling and closing its schools, leaving students stranded and generating a national debate on the sustainability of the voucher scheme.

Risk assessments should also include a frank accounting of the state's capacity to manage, regulate and monitor a PPP, and of potential private providers to meet the needs identified for a system. In a background paper prepared for the roundtable, Verger and Moschetti (2016: 8) noted that while PPPs might be able to address limitations of state provision in contexts of conflict and fragility, in practice "PPPs are very demanding and challenging forms of governance both for private agents and, especially, for governments." This is especially true in contexts where the capacity of states to plan, coordinate, regulate and finance private providers may be severely constrained (Rose and Greeley, 2006). As such, both balanced risk and shared responsibility are critical in partnership agreements. In practice, however, because the state has an obligation to fulfil the right to education, risk and responsibility are almost entirely born by the state. Consequently, when goals and responsibilities in partnerships are unmet, it is the state that is ultimately responsible (Verger and Moschetti, 2017). This implicit imbalance may mean that private partners engage in student selection "to minimize risk and maximize profit" (Verger and Moschetti, 2017) while leaving the burden of unprofitable or costly activities to the state, for example the schooling of vulnerable or remote communities or children with disabilities. Since private partners realize and capitalize on the role of the state as ultimately responsible for problems and failures, some may be led to take more risks than they would if these were equally shared.

Planning and systems development. From the outset of a potential partnership arrangement its reach should be clear to all stakeholders. Is the state embarking on a PPP as a small-scale experiment within the system or as a significant replacement for a part of, or as a supplement to, the existing system, for instance in 
contexts where public provision is insufficient or non-existent? A key area of debate is whether PPPs should be regarded as a temporary solution during which challenges with public provision are addressed, or a long-term policy option "through which the educational governance paradigm and the role of the state in education are altered more deeply" (Verger and Moschetti 2016). These different modalities imply different goals for the PPP, and therefore different strategies and responsibilities for implementation. Planning should also include the means for scaling up a successful pilot, or, on the other hand, transferring schools under a PPP arrangement back over to the state when their intended purpose has been met (Aubry, 2016).

Teachers' conditions. Cost-efficiencies in PPPs often result from the exploitation and casualization of teachers' labour and many private providers in PPP schemes have been found to restrict unionization, depress teachers' salaries and employ under-qualified teachers. This has been documented in many countries, such as in Concession schools in Bogota, Colombia (Edwards, DeMatthews and Hartley, 2017; Termes et al., 2015) and Uganda (ISER, 2016). Agreements about teachers' qualifications and labour conditions should be part of the minimum standards that states need to enforce within PPP arrangements.

Regulation and accountability. Accountability is a key component of PPP arrangements, but is also particularly challenging in contexts faced with difficulties in state capacity. Ideally, a PPP framework should establish from the outset mechanisms for holding providers accountable, include mechanisms for communication and knowledge-sharing between private provider(s) and the state, and creating monitoring and evaluation frameworks in which civil society is formally involved. Private providers should be required to provide open data about schools they operate both to the state and to the public. The state should define from the outset the goals and responsibilities of a PPP and how and for what private providers will be held accountable, not only legally but also through civil society/public engagement in monitoring and oversight. Real concerns exist about states' capacity to set and monitor minimum standards for education providers, as research conducted by civil society organizations has evidenced for Uganda, Ghana, Kenya and Pakistan. Regulation and monitoring is time- and resource-intensive and necessitates strong administrative capacities on the part of the 
state, which may be especially challenging, and therefore inadvisable, in conflict-affected and fragile contexts. Moreover, as noted by Verger and Moschetti (2016) in a background paper prepared for the PPP roundtable, enforcing compliance with basic regulations, such as non-selection or tuition, may create difficulties when schools are operated by for-profit actors driven by competitive incentives.

In a convening focused on accountability in relation to PPPs in education that took place in November 2015, hosted by the Open Society Initiative for Southern Africa in Johannesburg, and which brought together around 20 academics, researchers, human rights NGOs, low-fee private school providers and foundations from different countries, participants questioned whether in the case of an extremely weak state (i.e., a government having very limited capacity to govern an education system), education PPPs make any sense at all without the meaningful engagement of a public counterpart (state or citizens) in an arrangement premised on 'partnership'.

Participants emphasized that accountability systems are multistakeholder systems that work in different and interrelated directions and should involve all stakeholders. Additionally, different accountability mechanisms have different effects (e.g., punishment or support) and (political) implications, and as such, participants considered it imperative that a social justice perspective is not lost when analyzing or giving consideration to accountability in relation to education PPPs. Related to this, the purpose of introducing a particular mechanism should be clear, for example, to prevent exclusion of some groups/populations. Similarly, education PPPs should be introduced for a clearly-defined purpose and justified in terms of risks and contributions to quality, equality, social cohesion and pertinence. Finally, participants identified a need to define and give meaning to the concept of partnership, one that assumes a similar level of power between the actors involved. Unpacking how the condition of "fragile state" is defined might also prevent initiatives from bypassing the state, on the one hand, and helping define how a partnership agreement might contribute to addressing state financial or institutional capacity to provide education, on the other.

These interrelated issues and points of agreement have contributed to a consideration of principles under which states might limit 
or develop PPPs in education in line with their obligations as part of a process to develop a set of human rights Guiding Principles related to private actors in education, as discussed in the next section.

\section{APPLYING A HUMAN RIGHTS FRAMEWORK TO PPPs}

Since 2013, a number of civil society organizations from the education and human rights fields have jointly explored the application of the human rights framework, and specifically the right to education, to the increased participation of private actors in education. Part of this work has entailed unpacking the scope of right to education, and determining what it means in practice and how it applies to private actors. Several assumptions underpin this work. The first is that there is a need to develop a normative framework applicable to the role of private provision both for assessment of the impact of changes in education governance on the right to education and for developing operational accountability standards for private actors. The second is that a human rights framework offers a way forward in a polarized debate that is largely focused on the merits or demerits of private-sector involvement in education, as mentioned in the introduction. Aubry and Dorsi (2016) argue that while open to interpretation, the nearly universally legally-binding nature of human rights law related to education render it an appropriate framework to address what they term the "normative privatization debate." They argue that the controversy around the growth of private actors in education is partially explained by the weight given to different dimensions or concepts, such as equity or choice, in policy discussions, which in turn have implications for how research is conducted, construed and used by policy makers and other actors. By this reasoning, human rights law, in contrast, provides a generally-uncontested lens through which to approach a highly contentious issue. 
A large part of this work is informed by ongoing empirical research conducted in nearly a dozen countries ${ }^{7}$ since 2014 to assess the impact of the existence or growth of private actors in education - largely the rapid expansion of low-fee private schools, for-profit chains, and various public-private partnerships - against human rights standards. The Global Initiative for Economic, Social and Cultural Rights (GI-ESCR) and Right to Education Initiative (RTE) have spearheaded this work in collaboration with national and international partner organizations, including human rights NGOs and national education coalitions, to review laws, policies and secondary literature in different countries on the impact of private actors in education applying the human rights framework, and specifically the right to education. This research has been compiled in reports that have been presented, alongside state reports, to regional or UN human rights mechanisms ${ }^{8}$ which periodically review the implementation of human rights conventions by states. On the basis of information presented to them, the expert committees make observations highlighting progress made, challenges and areas of concern, and make concrete recommendations to states. These observations are quasi-legal interpretations of the right to education, which means that they are considered within the scope of international law, and have in turn contributed to informing a set of human rights Guiding Principles on state obligations with regard to private education provision.

Two developments in this work are important to highlight. First, the concluding observations made by these mechanisms have contributed to providing clarity on how the right to education

7 These include Brazil, Chile, Ghana, Haiti, Kenya, Morocco, Pakistan, the Philippines, Uganda and Nepal. The United Kingdom was reviewed with regard to its support through development aid for private education, including low fee private schools and public-private partnerships, in developing countries including Kenya and Pakistan.

8 These treaty body mechanisms are committees of independent experts established by states to monitor the implementation, and provide guidance on the interpretation, of human rights treaties. Each convention has a different group of experts that periodically reviews state party fulfilment of their obligations under different conventions. States prepare reports every five years on the situation in their country, and civil society also has the opportunity to present its analysis as part of the review process. On the basis of these country reports and other sources, the experts ask questions and make observations highlighting progress made, challenges, areas of concern and make recommendations to states. 
applies to particular situations as well as the complex dynamics that affect its implementation, specifically the growth of private actors and public-private arrangements. Research on public-private partnerships frameworks have been undertaken by civil society organizations in Brazil, Chile, Haiti, Pakistan and Uganda and have to date resulted in more than 20 concluding observations that spell out recommendations on the role of private actors in education (GI-ESCR, 2017). ${ }^{9}$ For example, regarding PPPs in education, the UN Committee on Economic, Social and Cultural Rights (CESCR) recommended that Chile:

[T]ake the necessary measures to ensure that the reform of the education system eliminates all mechanisms that result in the discrimination and segregation of students based on their social or economic background and, inter alia, ensure the effective implementation of the Inclusive Education Act, which regulates school admissions, eliminates partial fee-paying and stipulates that educational establishments receiving State support must be non-profit-making. (CESCR, 2015)

For Haiti, the UN Committee on the Rights of the Child (CRC) recommended that the government: "Ensure that public-private partnerships do not impede access to quality education for all children and guarantee that they do not serve private interests or entail any form of commercialization of education" (CRC, 2016).

Second, the clarity afforded by this work has brought nuance into discussions on the role of private actors, such as the roundtable convening on PPPs, where empirical research from Uganda and Haiti used to inform UN treaty bodies was discussed. This work has also opened up spaces for dialogue at the national level. In Uganda, for example, advocacy around the concluding observations of the UN CESCR and the African Commission on Human and Peoples' Rights, public awareness-raising and convening of stakeholder dialogues on PPPs at the national level, led by the Initiative for Social and Economic Rights, have resulted in their involvement in ongoing reviews of the government's PPP policy.

9 A summary of these recommendations, updated on a regular basis, can be found on the website of the Global Initiative for Economic, Social and Cultural Rights: http://bit.ly/synthesisprivatisation. 
This body of work has been based on, and has contributed to shaping, an evolving human rights analysis framework, ${ }^{10}$ developed jointly by GI-ESCR and RTE, ${ }^{11}$ a tool which designates the legal criteria, or conditions drawn from human rights law, that the operation of private schools should not undermine. Broadly summarized, where private providers are involved in education, they should: not be a source of segregation, discrimination and inequalities; provide an alternative to and not undermine access to free quality education; preserve the humanistic nature of the right to education; conform to minimum education standards established and enforced by governments; and be regulated by norms that are developed following due process and participation in education decision making. ${ }^{12}$ As described by Aubry and Dorsi (2016: 7):

These criteria are inter-connected, may partly overlap, and they represent a sort of red line: if the existence or growth of private actors in education affects negatively any of those criteria, it is not acceptable, and likely, a violation of human rights law. Conversely, when all of these criteria are met, the role of private actors in education is acceptable under the human rights normative framework. Importantly, these criteria apply to States in the management of their domestic education system, but also equally to donor States, which should respect those criteria when funding education systems - including private schools - in other countries.

Building on the framework developed by GI-ESCR and RTE, an informal network of civil society organizations who coordinate activities related to privatization in education and human rights, started a process in 2015 to develop a set of human rights Guiding Principles that compile and restate existing human rights standards

10 The so-called "Privatisation in education Assessment Framework" (PAF) is a methodology or tool to be used to assess the involvement and growth of private actors in education against the right to education. See: http://www.right-toeducation.org/sites/right-to-education.org/files/resource-attachments/RTE_GIESCR _Methodological_Guide_Privatisation_and_Human_Rights_2016_En_0.pdf, accessed 7 February 2018.

11 Formerly the Right to Education Project. Until 2016, the Right to Education Project was hosted by ActionAid International as a collaborative initiative of the Global Campaign for Education, Human Rights Watch, Action Aid and Save the Children, and is now an independent charity under UK law.

12 For a more in depth discussion of these criteria or dimensions, see: Aubry and Dorsi (2016). 
as they relate to private actors in education. ${ }^{13}$ These Guiding Principles aim to reflect existing legally-binding international instruments and national law, rather than create new standards, and are to be directly applicable to hold states accountable for their obligations to fulfil and protect the right to education. This ongoing process has entailed a series of regional and expert consultations that brought together stakeholders ${ }^{14}$ from around the world to participate in developing the draft Guiding Principles. This normative framework is scheduled to be finalized and validated by a group of experts in international law and education towards the end of 2018, with the aim of being both operational and adaptable to different contexts.

One of the most difficult issues to settle is whether it is compatible with human rights agreements and law for states to fund private actors to deliver the right to free education. While the right to free quality education is unequivocal at the basic level, less clear is whether such education should be provided directly by the state, or whether this can be delivered through the funding of private delivery or private management of public schools under a PPP arrangement. If such arrangements are compatible with human rights, to what extent and under what conditions are they compatible? When a state considers entering into a partnership arrangement, further questions arise about the kinds of schools involved. Is funding private education for community schools, religious schools and other organizations that are dependent on public funding (e.g.,

13 The development of the Guiding Principles is facilitated by five organizations acting as a Secretariat for the process and including Amnesty International, the Equal Education Law Centre, the Global Initiative for Economic, Social and Cultural Rights, the Initiative for Social and Economic Rights and the Right the Education Initiative.

14 Between August 2016 and December 2017, consultations were organized in Bangkok (August 2016) for stakeholders in the Asia Pacific region, Nairobi for East Africa (September 2016), Paris for Europe and North America (March 2017), Johannesburg for Southern Africa (August 2017) and Dakar for stakeholders from Francophone countries in Africa as well as Haiti (October 2017), and further smaller convenings during workshops at the Comparative International Education Society Conference (2016 and 2017), the ANCEFA Regional Education Policy Forum (2016) and an OSF convening on the impact of strategic litigation on access to quality education in Sao Paulo (2017). These consultations have brought together representatives of civil society organizations including teachers' and student organizations, ministries of education, private actors, academics, legal experts and international organizations. 
denominational schools in many countries that have historically partnered with the state) compatible with a human rights framework? Are only those schools that are free, non-selective and adequately-regulated acceptable in this concept? Are for-profit and commercially-oriented providers intrinsically incompatible with the development of equitable and inclusive education systems?

These questions are also the basis of contention among civil society organizations on the issue, with some considering that no private schools should receive public funding as this could encourage education privatization and create or further entrench inequalities, and others contending that the funding of private schools might be necessary, and legally acceptable, in certain instances and under certain conditions. For example, in a crisis-affected context where the state is unable to provide sufficient and appropriate education services in the short term, PPPs might offer a way forward. However, rather than PPPs involving market approaches and creating dependence on the private sector, in such contexts states could try to build multi-stakeholder and capacity-building oriented partnerships with "a broad range of state and non-state partners including universities, local and international NGOs, grassroots organizations, international aid agencies" (Verger and Moschetti 2017: 261).

While states have the obligation to guarantee free quality basic education, they have some freedom under human rights law as to how this obligation is realized (Aubry, 2016), which may include funding of private schools. In most circumstances, states are considered as having the primary responsibility for direct provision of education, however private delivery in education supported by the state under a PPP arrangement, is not in principle at odds with human rights law, if it can be demonstrated that it does not undermine the realization of human rights principles. A case that demonstrates the opposite is the large-scale voucher system in Chile which was found to undermine the right to non-discrimination and equality and increase socio-economic segregation between schools (Valenzuela, Bellei and De los Rios, 2013). The five areas that GI-ESCR, RTE and partners have identified begin to provide an understanding of the limitations of this freedom and the legal criteria or conditions under which private actors might provide education services, including in a PPP arrangement. 
What I have argued in this text, and that is illustrated by all the chapters in this book, is that in practice PPPs cover a broad range of policy options and follow different rationales. In education there are numerous challenges and limitations to their implementation and governance (Languille, 2017). A PPP that appears to be compatible with human rights at its conception may be found to undermine human rights at a later stage, when it is very difficult to reform or abolish. Some of these challenges are being explored in a series of background papers that have been commissioned by the Open Society Foundations and the five organizations guiding the process, to unpack and explore key concepts and questions in relation to the Guiding Principles through a theoretical analysis of existing law and literature related to private actors in education. These include an exploration of whether PPPs are acceptable in education from a social justice perspective, whether public funding of private actors is an option compliant with human rights law to realize the right to education, and the limitations of school choice.

\section{CONCLUSION}

This chapter has discussed efforts by a range of stakeholders in education to address, from a human rights and social justice perspective, questions around the assumption by private actors of responsibilities for delivery of education. These efforts have broadly entailed research, convenings and advocacy over a four-year period to address questions of accountability, equity and social cohesion in relation to the growth of private actors in education. What has emerged is a work in progress to provide a baseline and operations interpretation of the application of the human rights framework to the role of private actors and PPPs in education.

While these are ongoing efforts, three observations are critical to highlight: the first is that the various convenings to discuss specific aspects of PPPs in education, such as their role in fragile and conflict-affected settings, accountability in relation to PPPs, and consultations to input on the Guiding Principles specifically regarding public funding of private schools, have brought together different actors and stakeholders with different perspectives, positions and agendas, who might normally not engage with each other. This is significant, as it opens up a space for critical and constructive 
debate on a highly contentious topic and attempts to involve all relevant stakeholders at different levels. Crucial to such a debate is a clear framing or lens through which to reflect on these issues. Here the nearly universally-agreed human rights system offers an appropriate lens to explore this issue from the obligations of states and responsibilities of private actors. Second, these convenings and efforts to develop a normative framework allow different actors to scrutinize their own positions, test their assumptions and to consider alternative perspectives, particularly given the increasingly complex arrangements and multiplicity of actors involved in education delivery. Third, while the purpose of these collective efforts is ultimately to inform policy, interventions and advocacy that might lead to the meaningful implementation of the right to education, the process is equally critical for clarifying areas of agreement and disagreement on complex governance arrangements such as public-private partnerships in education and their limitations from a human rights perspective.

The outcome of this work with be a further normative clarification of the application of the human rights framework to the role of private actors in education, providing different tools for stakeholders to hold actors to account for inequalities in education.

\section{REFERENCES}

Adamson, F. and L. Darling-Hammond (2016). The critical choice in American education: privatization or public investment? in F. Adamson, B. Åstrand and L. Darling-Hammond (eds), Global Education Reform. How Privatization and Public Investment Influence Education Outcomes. New York: Routledge: 131-168.

Al Jazeera. The Stream. (2016). Outsourcing Liberia's Education System. Al Jazeera, 12 April. Retrieved 6 February 2018 from: http://stream.aljazeera. com/story/201604121525-0025188.

Aubry, S. (2016). When is state funding of private schools a violation of human rights? Global Education Monitoring Report World Education Blog, 23 June. Retrieved 6 February 2018 from: https://gemreportunesco.word press.com/2016/06/23/when-is-state-funding-of-private-schools-a-violationof-human-rights/.

Aubry, S. and D. Dorsi (2016). Towards a human rights framework to advance the debate on the role of private actors in education. Oxford Review of Education, 42(5), 612-628. 
CESCR (UN Committee on Economic, Social and Cultural Rights). (2015). Concluding observations: Chile, E/C.12/CHL/C O/4. Retrieved 6 February 2018 from: http://bit.ly/1 RWOPkD.

CRC (UN Committee on the Rights of the Child) (2016). Concluding observations: Haiti, CRC/C/HTI/CO /2-3. Retrieved 6 February 2018 from: http://bit.ly/1 TIaPTM.

Draxler, A. (2008). New Partnerships for EFA: Building on Experience. UNESCO-IIEP/World Economic Forum. Retrieved 6 February 2018 from: http://unesdoc.unesco.org/images/0015/001567/156753e.pdf.

Draxler, A. (2012). International PPPs in education: new potential or privatizing public goods? in S. Robertson, K. Mundy, A. Verger and F. Menashy (eds), Public Private Partnerships in Education: New Actors and Modes of Governance in a Globalizing World. Cheltenham, UK and Northampton, MA, USA: Edward Elgar Publishing: 43-62.

Edwards, D.B., DeMatthews, D. and H. Hartley (2017). Public private partnerships, accountability, and competition: theory versus reality in the Charter Schools of Bogota, Colombia. Education Policy Analysis Archives, 25 (10). Retrieved 6 February 2018 from: http://epaa.asu.edu/ojs/article/view/2556.

Gideon, J. and E. Unterhalter (2017). Exploring public private partnerships in health and education: a critique. Journal of International and Comparative Social Policy, 33 (2), 136-141. Retrieved 6 February 2018 from: http:// www.tandfonline.com/doi/full/10.1080/21699763.2017.1330699.

GI-ESCR (Global Initiative for Economic, Social and Cultural Rights). (2017). Human rights bodies statements on private education September 2014 November 2017. Retrieved 6 February 2018 from: http://bit.ly/synthesis privatisation.

ISER (Initiative for Social and Economic Rights). (2016). A threat or opportunity? Public private partnerships in education in Uganda. Retrieved 6 February 2018 from: https://www.iser-uganda.org/images/downloads/Threat_ or_Opportunity_Public_Private_Partnership_in_Education_in_Uganda.pdf.

Languille, S. (2017). Public-private partnerships in education and health in the global south: a literature review. Journal of International and Comparative Social Policy, 33 (2), 142-165.

Mungai, C. (2016). An Africa first! Liberia outsources entire education system to a private American firm. Why all should pay attention. Mail \& Guardian Africa, 31 March. Retrieved 6 February 2018 from: http://mgafrica.com/ article/2016-03-31-liberia-plans-to-outsource-its-entire-education-system-toa-private-company-why-this-is-a-very-big-deal-and-africa-should-pay-attention .

OECD (Organisation for Economic Co-operation and Development). (2015). Improving schools in Sweden: an OECD perspective. Retrieved 6 February 2018 from: http://www.oecd.org/edu/school/Improving-Schools-in-Sweden. pdf.

OSF (Open Society Foundations) and INEE (International Network for Education in Emergencies). (2016). Concept roundtable discussion: exploring public private partnerships in crisis-affected and fragile states. Unpublished. 
Patrinos, H.A., Barrera Osorio, F. and J. Guaqueta (2009). The Role and Impact of Public-Private Partnerships In Education. Washington, DC: World Bank Publications.

Minow, M. (2003). Public and private partnerships: accounting for the new religion. Harvard Law Review, 116 (5), 1229-1270.

Robertson, S.L., Mundy, K.E., Verger, A. and F. Menashy (2012). Public Private Partnerships in Education: New Actors and Modes of Governance in a Globalizing World. Cheltenham, UK and Northampton, MA, USA: Edward Elgar Publishing.

Robertson Aslam, M., Rawal, S. and S. Saeed (2017). Public-private partnerships in education in developing countries: a rigorous review of the evidence. Ark Education Partnerships Group. Retrieved 6 February 2018 from: http://arkonline.org/sites/default/files/ArkEPG_PPP_report.pdf.

Rose, P. and M. Greeley (2006). Education in fragile states: capturing lessons and identifying good practice. Draft Paper Prepared for the Development Assistance Committee Fragile States Working Groups, Service Delivery Workstream, Subteam for Education Services.

Rosenberg, T. (2016, 14 June). Liberia, desperate to educate, turns to charter schools. The New York Times. Retrieved 6 February 2018 from: https:// www.nytimes.com/2016/06/14/opinion/liberia-desperate-to-educate-turns-tocharter-schools.html?ref=opinion\&_r=0.

Termes, A., Bonal, X., Verger, A. and A. Zancajo (2015). Public-private partnerships in Colombian education: the equity and quality implications of 'Colegios en concesión'. ESP Working Paper Series; No. 78. Privatisation in Education Research Initiative. Retrieved 6 February 2018 from: http:// www.periglobal.org/sites/periglobal.org/files/WorkingPaper66\%20PPPs.pdf.

Valenzeula, J.P., Bellei, C. and D. De los Rios (2013). Socioeconomic school segregation in a market-oriented education system. The case of Chile. Journal of Education Policy, 29 (2), 217-241. Retrieved 6 February 2018 from: https://doi.org/10.1080/02680939.2013.806995.

Verger, A. and M. Moschetti (2016). Public private partnerships in education: exploring different models and policy options. Background Paper (unpublished) prepared for the OSF/INEE Roundtable "Exploring Public Private Partnerships in Crisis-Affected \& Fragile States" on 27-28 June 2016.

Verger, A. and M. Moschetti (2017). Partnering with the private sector in the post-2015 era? The main political and social implications in the educational arena, in SOLIDAR (2017). Progressive Lab for Sustainable Development: From Vision to Action. Brussels: Foundation for European Progressive Studies: 245-269. 